\title{
Postsynaptic Potentiation of Neurotransmission by Neurokinin A in Rat Vas Deferens
}

\author{
Koichi Nagata, Hiroshi Saito and Norio Matsuki* \\ Department of Chemical Pharmacology, Faculty of Pharmaceutical Sciences, The University of Tokyo, \\ Tokyo 113, Japan \\ Received October 11, 1991 Accepted January 4, 1992
}

\begin{abstract}
Effects of neurokinin A (NKA) on sympathetic neurotransmission were studied in rat vas deferens. Although neither prazosin, an $\alpha_{1}$-adrenoceptor blocker, nor $\alpha, \beta$-methylene adenosine triphosphate, a $\mathrm{P}_{2}$-purinoceptor blocker, inhibited the NKA-induced contractions in the epididymal site, high concentration of NKA-induced contractions in the prostatic site were slightly decreased by either of the two blockers. Treatment with guanethidine, which prevents the release of sympathetic transmitters from presynaptic nerve endings, also had no effect on NKA-induced contractions in either site. To investigate the effects of NKA on the adrenergic and purinergic neurotransmission in more detail, we measured transmitter release by using $\left[{ }^{3} \mathrm{H}\right]$ norepinephrine or $\left({ }^{14} \mathrm{C}\right]$ adenosine. Neither spontaneous or nor evoked ${ }^{3} \mathrm{H}$ efflux, indicating NE release, was affected by NKA in either site. NKA enhanced ${ }^{14} \mathrm{C}$ efflux, indicating ATP release, evoked by electrical stimulation in the epididymal site, which may be originated from smooth muscle. In the prostatic site, contractions induced by electrical stimulation were enhanced in spite of no increase in ${ }^{3} \mathrm{H}$ or ${ }^{14} \mathrm{C}$ efflux. These results suggest that: 1) NKA has no effect on presynaptic nerve terminals in both sites, 2) NKA potentiates the effects of neurotransmitters in the prostatic site, and 3) NKA modulates the neurotransmission.
\end{abstract}

Neurokinin A (NKA), which is structurally related to substance $P$, exerts a great variety of effects on various tissues $(1-3)$. Rat vas deferens is a good model for investigating sympathetic neurotransmission, and its adrenergic and purinergic properties have been extensively characterized.

It is well-known that the smooth muscle of the rat vas deferens receives a dense plexus of adrenergic fibers, and stimulation of the hypogastric nerve mainly results in an overflow of endogenous NE from the tissue. Much evidence has also shown that ATP is released by

*To whom correspondence should be addressed. nerve stimulation $(4-8)$ and induces contraction $(9-11)$ in several sympathetically innervated tissues, including rat vas deferens. The presence of $\mathrm{NK}_{2}$ receptors both in the autonomic nerves and in the smooth muscle of rat vas deferens has been reported, and potentiation of electrical stimulation-evoked twitches by NKA in the prostatic site was regarded as a result of facilitating release of transmitters (12). However, under this condition, both presynaptic and postsynaptic effects can equally contribute to the potentiation. In the previous report (13), we have characterized NKA-induced contractions of rat vas deferens and demonstrated that there are region-dependent 
differences in $\mathrm{Ca}^{2+}$ utilization. The data suggested a neuromodulatory role of NKA.

In the present study, effects of NKA on the release of transmitters were investigated by a radiochemical technique and by measuring the mechanical responses to elucidate the mechanism of NKA-induced contractions. The region-dependent differences were also studied.

\section{MATERIALS AND METHODS}

\section{Measurement of contraction}

Experimental conditions were the same as in our previous report (13). Briefly, male Wistar rats $(250-350 \mathrm{~g})$ were killed by a blow on the head, and then the vas deferens was excised and the epididymal and prostatic sites, each representing $40 \%$ of the total organ length from either end, were obtained. The preparation was vertically mounted in a $5-\mathrm{ml}$ organ bath containing physiological salt solution (PSS) of the following composition: 118.0 $\mathrm{mM} \mathrm{NaCl}, 4.7 \mathrm{mM} \mathrm{KCl}, 1.8 \mathrm{mM} \mathrm{CaCl}, 1.2$ $\mathrm{mM} \quad \mathrm{MgCl}_{2}, 1.2 \mathrm{mM} \quad \mathrm{NaH}_{2} \mathrm{PO}_{4}, \quad 25.0 \mathrm{mM}$ $\mathrm{NaHCO}_{3}$ and $11.1 \mathrm{mM}$ glucose, $\mathrm{pH} 7.4$; the solution was continuously oxygenated with a mixture of $95 \% \quad \mathrm{O}_{2}$ and $5 \% \quad \mathrm{CO}_{2}$ at $37^{\circ} \mathrm{C}$. Each preparation was allowed to equilibrate for $1 \mathrm{hr}$ under an initial tension of $5 \mathrm{mN}$. Isometric contraction was measured with a force displacement transducer (TB 612T, Nihon Kohden) and recorded on an ink-writing oscillograph (WI612-G, Nihon Kohden). Concentration-response curves were obtained by non-cumulative addition of each concentration of the agent.

The transmural electrical stimulations were applied through two platinum electrodes. Ten square wave stimulating pulses (duration: 1 msec) at the frequency of $10 \mathrm{~Hz}$ were delivered in a train during every $30 \mathrm{sec}$. This type of stimulation has no direct effect on smooth muscle and induced transmitter release from presynaptic nerve endings, since the contraction was completely abolished in the presence of $10^{-6} \mathrm{M}$ tetrodotoxin or guanethidine.

\section{Measurement of release of transmitter}

The method described by Vizi and Burnstock (14) was used with minor modification. The vasa from each site was incubated in the PSS containing levo-[ring- $\left.2,5,6-{ }^{3} \mathrm{H}\right]$ norepinephrine $(\mathrm{NE})\left(5.6 \times 10^{5} \mathrm{~Bq} / \mathrm{ml}\right.$, New England Nuclear) or $\left[8-{ }^{14} \mathrm{C}\right]$ adenosine $(7.4 \times$ $10^{3} \mathrm{~Bq} / \mathrm{ml}$, New England Nuclear) for $30 \mathrm{~min}$. During the incubation, the medium was bubbled with $95 \% \mathrm{O}_{2}$ and $5 \% \mathrm{CO}_{2}$ and maintained at $37^{\circ} \mathrm{C}$. After the incubation, the vasa were washed several times with the PSS and vertically mounted in a $2-\mathrm{ml}$ organ bath under an initial tension of $5 \mathrm{mN}$.

The preparations were superfused $(0.87$ $\mathrm{ml} / \mathrm{min}$ ) continuously with the PSS containing ascorbic acid $\left(3 \times 10^{-3} \mathrm{M}\right)$ and disodium ethylenediamine tetraacetate ( $\mathrm{Na}_{2}$ EDTA: $10^{-4}$ M). The effluent was discarded for the initial $50 \mathrm{~min}$. Subsequently, fractions were collected every $3 \mathrm{~min}$ with a fraction collector (SF100G, Toyo).

The tissues were stimulated transmurally through a pair of platinum electrodes. To mimic the physiological outflow, intermittent pulse train stimulation was used. Five square wave stimulating pulses with supramaximal voltage (duration: $1 \mathrm{msec}$ ) were delivered in a train, at the rate of $20 \mathrm{~Hz}$, every $2 \mathrm{sec}$ for 3 min (450 pulses in total). Under these conditions, transmitter release is considered to be subject to presynaptic modulation. The electrical stimulation was repeated several times with an interval of $30 \mathrm{~min}$ in the absence and presence of test compounds.

The ratios between the amounts of released radioactivities and contractions during two consecutive stimuli were taken as an indicator of drug effect. After collections of all the fractions, the radioactivities of ${ }^{3} \mathrm{H}$ or ${ }^{14} \mathrm{C}$ in the perfusate and the tissue were counted as follows. Part of each fraction $(0.5 \mathrm{ml})$ was mixed with $5 \mathrm{ml}$ toluene-based scintillator containing $33 \%(\mathrm{v} / \mathrm{v})$ Triton X-100. Radioactivity was determined in a liquid scintillation counter (Aloka LSC-700). The tissues were blotted with filter papers, weighed and solubilized in $0.4 \mathrm{ml}$ Soluene 350 (United Technologies 
Packard) at about $45^{\circ} \mathrm{C}$. The radioactivity in $0.1 \mathrm{ml}$ samples of the tissue solution was measured and converted to the content in one $g$ tissue. The counts of the radioactivity released was expressed in $\mathrm{Bq} / \mathrm{g}$ tissue and as a fractional rate, i.e., the release was expressed as a percentage of the amount of radioactivity in the tissue at the time when the collection of the fraction was started. Isometric contraction of the preparations loaded with $\left[{ }^{3} \mathrm{H}\right] \mathrm{NE}$ or $\left[{ }^{14} \mathrm{C}\right]$ adenosine were measured simultaneously.

\section{Statistical analysis}

Data were expressed as the mean \pm S.E. Significance of the difference was determined by Student's $t$-test.

\section{Drugs and Chemicals}

Drugs used were obtained from the following sources: adenosine triphosphate (ATP), $\alpha, \beta$-methylene-ATP $(\alpha, \beta$-me-ATP), guanethidine (Sigma); neurokinin A (Peptide Institute Inc.), L-norepinephrine bitartrate, prazosin and yohimbine (Wako). All other chemicals were of reagent grade.

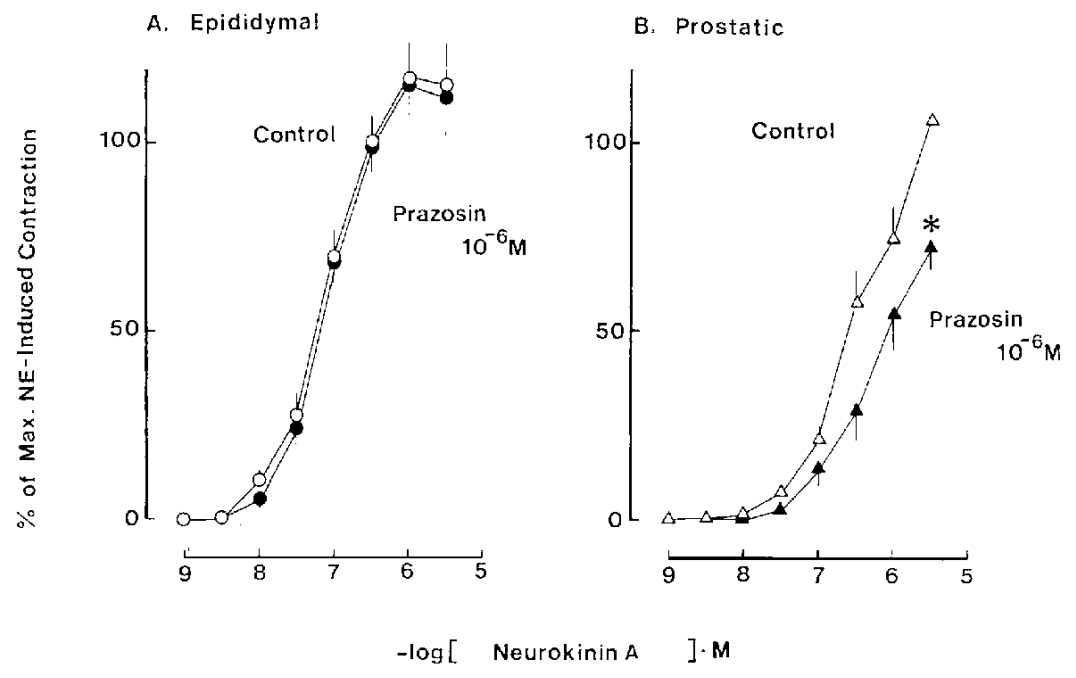

Fig. 1. Effects of $10^{6} \mathrm{M}$ prazosin on contractions induced by NKA in the epididymal (A) and the prostatic site (B) from rat vas deferens. Open and closed circles indicate contraction before and after treatment of prazosin, respectively. The abscissa indicates the negative logarithm of the molar concentration of NKA. The ordinatc indicates contraction expressed as a percentage of the maximal contraction induced by NE. Symbols and vertical bars indicate the mean \pm S.E. of four experiments. Astcrisk indicates a significant difference from control value $\left({ }^{*}: \mathrm{P}<0.05\right)$.

\section{RESULTS}

Effects of $\alpha_{1}$-adrenoceptor and $P_{2}$-purinoceptor blocker on NKA-induced contractions

Prazosin $\left(10^{-6} \mathrm{M}\right)$, which completely inhibited norepinephrine (NE)-induced contractions, did not affect NKA-induced contractions in the epididymal site (Fig. 1A), whereas it decreased them significantly in the prostatic site (Fig. 1B). $\alpha, \beta$-Me-ATP $\left(10^{-5} \mathrm{M}\right)$ did not significantly affect NKA-induced contraction in the epididymal site (Fig. 2A), but decreased the maximal contraction in the prostatic site (Fig. 2B). However, there was no difference in contraction in either site before and after the treatment with guanethidine $\left(10^{-6} \mathrm{M}\right)$, which completely abolished contractions induced by the electrical stimulation (data not shown). Therefore, we studied the effects of NKA on the release of neurotransmitters (NE and ATP) by using radiochemical detection to clarify whether or not NKA-induced contraction was partially attributable to NE and ATP released from presynaptic nerve endings.

B. Prostatic 
A. Epididymal

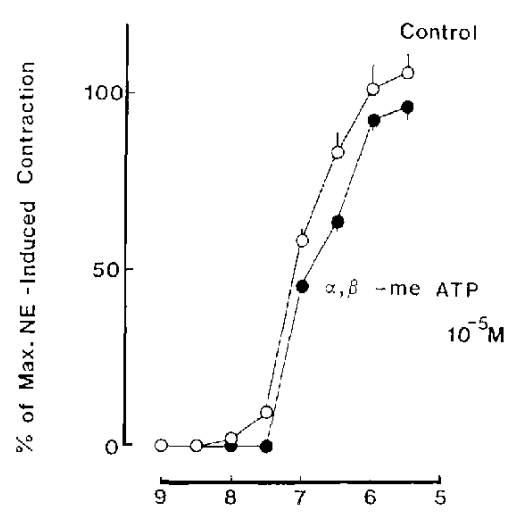

B. Prostatic

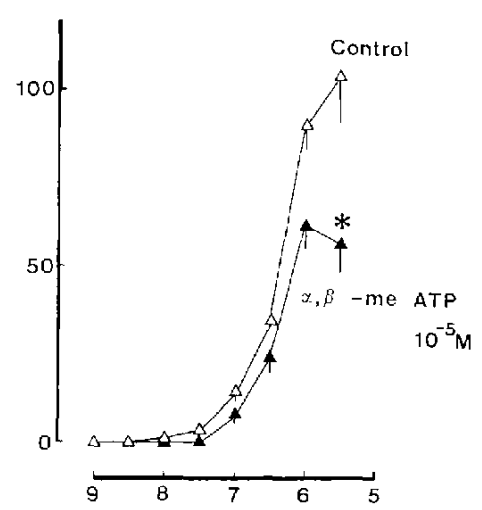

]$\cdot M$

Fig. 2. Effects of $10^{-5} \mathrm{M} \alpha, \beta$-me-ATP on contractions induced by NKA in the epididymal (A) and the prostatic site (B) from rat vas deferens. Open and closed circles indicate contraction before and after treatment of $\alpha, \beta$-me-ATP, respectively. The abscissa and ordinate are the same as in Fig. 1. Symbols and vertical bars indicate the mean \pm S.E. of four experiments. Asterisk indicates a significant difference from the control kalue (*: $\mathrm{P}<0.05)$.

Effects of NKA on spontaneous release of ${ }^{3} \mathrm{H}$ and ${ }^{14} \mathrm{C}$ efflux

After a 30-min loading with $\left[{ }^{3} \mathrm{H}\right] \mathrm{NE}$ or $\left[{ }^{14} \mathrm{C}\right]$ adenosine, followed by a 50 -min washout, the total radioactivities in the vas deferens were estimated to be $3.03 \pm 0.32 \times 10^{6}$ and $2.60 \pm 0.36 \times 10^{4} \mathrm{~Bq} / \mathrm{g}$ tissue in the epididymal site and $1.40 \pm 0.14 \times 10^{6}$ and $8.33 \pm 2.01 \times 10^{4} \mathrm{~Bq} / \mathrm{g}$ tissue in the prostatic site, respectively. The rates of spontaneous radioactive efflux were constant and not different between the epididymal and prostatic site. During the 3-min collection period, $0.85 \pm$ $0.04 \%$ and $0.74 \pm 0.05 \%$ of the ${ }^{3} \mathrm{H}$-content $1.57 \pm 0.21 \%$ and $1.31 \pm 0.10 \%$ of the ${ }^{14} \mathrm{C}$ content were spontaneously released in the epididymal and prostatic site, respectively.

Although NKA $\left(10^{-7}\right.$ to $\left.3 \times 10^{-6} \mathrm{M}\right)$ had no effect on the spontaneous ${ }^{3} \mathrm{H}$ efflux (NE release), $10^{-6} \mathrm{M}$ NKA tended to increase the ${ }^{14} \mathrm{C}$ efflux (ATP release) in the prostatic site (Fig. 3). However, in the prostatic site, the increase of ${ }^{14} \mathrm{C}$ efflux by $10^{-6} \mathrm{M}$ NKA was not affected by $10^{-6} \mathrm{M}$ guanethidine, which completely abolished the stimulation-evoked release (Fig. 4). These results suggest that the increase in the ${ }^{14} \mathrm{C}$ efflux may be attributed to a release from muscle as a result of membrane depolarization or contraction and that NKA has no effect on the release of transmitters.

\section{Effects of NKA on ${ }^{3} \mathrm{H}$ and ${ }^{14} \mathrm{C}$ efflux evaked by electrical stimulation \\ In response to the field stimulation with} trains of 450 pulses, $2.38 \pm 0.16 \%$ and $2.26 \pm$ $0.09 \%$ of the ${ }^{3} \mathrm{H}$-content and $2.35 \pm 0.34 \%$ and $2.23 \pm 0.20 \%$ of the ${ }^{14} \mathrm{C}$-content in the tissue were released in the epididymal and the prostatic site, respectively. The ${ }^{3} \mathrm{H}$ and ${ }^{14} \mathrm{C}$ efflux evoked by electrical stimulation was fairly constant and not changed by the application of $10^{-6} \mathrm{M}$ NKA.

The rat vas deferens responded to the field stimulation with an initial twitch followed by a sustained contraction. It is well-documented that the twitch response is due to the release of ATP and the sustained response is attributable to released NE $(9,14)$. NE- and ATPcomponents of evoked contractions were inhibited by prazosin $\left(10^{-6}\right.$ to $\left.10^{-4} \mathrm{M}\right)$ and $\alpha, \beta$ me-ATP $\left(10^{-5} \mathrm{M}\right)$, respectively (four experiments). Therefore, these contractions induced 
A. ${ }^{3} \mathrm{H}$ release

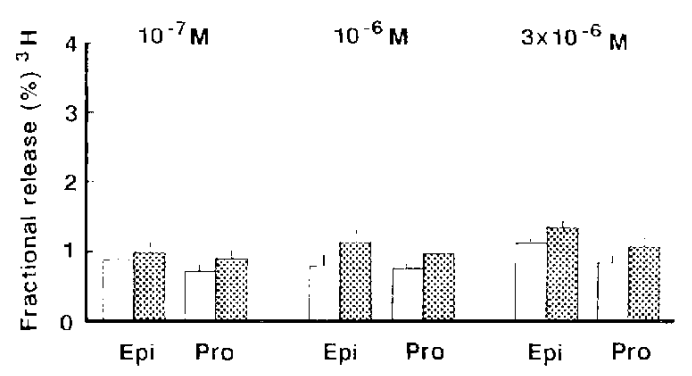

B. ${ }^{14} \mathrm{C}$ release

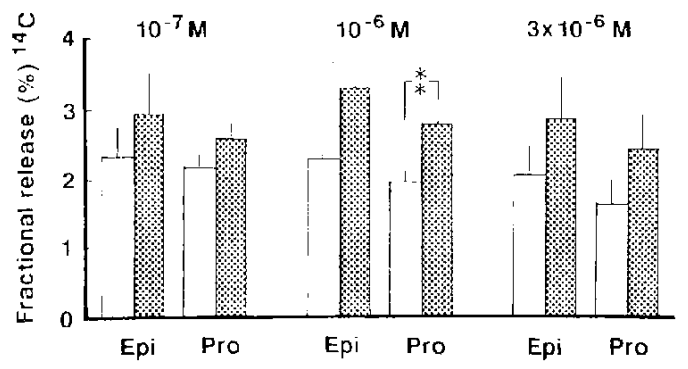

Fig. 3. Effects of NKA $\left(10^{-7} \mathrm{M}, 10^{6} \mathrm{M}\right.$ and $3 \times$ $10^{-6} \mathrm{M}$ ) on resting efflux of ${ }^{3} \mathrm{H}$ (A) or ${ }^{14} \mathrm{C}$ (B) from rat vas deferens previously loaded with $\left[{ }^{3} \mathrm{H}\right] \mathrm{NE}$ or $\left[{ }^{14} \mathrm{C}\right]$ adenosine, respectively. The ordinate indicates fractional release of radioactivities expressed as a percentage of estimated total radioactivities in the tissue at the beginning of the perfusion. Epi and Pro mean the epididymal and the prostatic site, respectively. Open and stippled columns indicate the average of released radioactivity for $15 \mathrm{~min}$ before and after NKA perfusion, and vertical bars indicate the S.E. of four experiments. Asterisks indicate a significant difference from the control value $\left({ }^{* *}: \mathrm{P}<0.01\right)$.

by electrical stimulation were separated into the two components, and the ratios between the contractions induced by the consecutive stimulations were calculated.

Figure 5 summarizes the effects of NKA on the release and the contraction induced by electrical stimulation. Perfusion of $10^{-6} \mathrm{M}$ NKA was started at $15 \mathrm{~min}$ after the first electrical stimulation and continued for $30 \mathrm{~min}$. The ratio of reieased radioactivities of the first and the second electrical stimulations $\left(S_{2} / S_{1}\right)$ was taken as an indicator. The electrical stimulation-evoked contractions were also ex-

\section{A. Contraction}

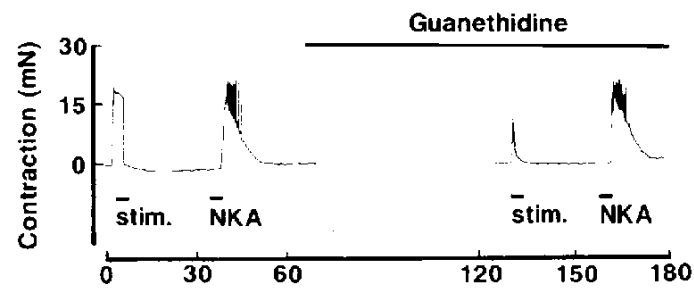

\section{B. Release}

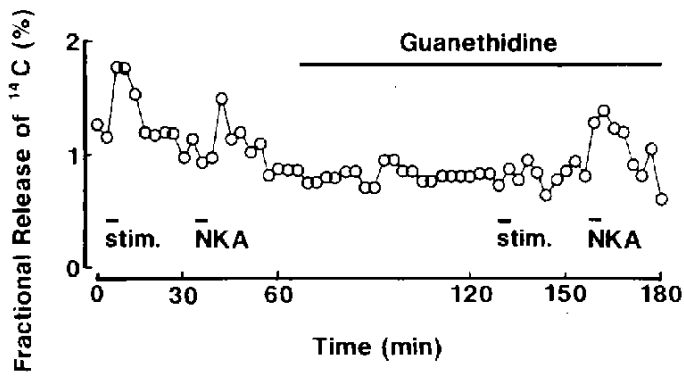

Fig. 4. Effects of $10^{-6} \mathrm{M}$ guanethidine on contractions (A) and efflux of ${ }^{14} \mathrm{C}$ (B) induced by $10^{-6} \mathrm{M}$ NKA or electrical stimulation in the prostatic site. The ordinate in (A) indicates contraction and that in $(B)$ is the same as in Fig. 3. Horizontal solid bars (stim. and NKA) indicate the period of application of electrical stimulation or NKA.

pressed as the ratio of contractions evoked by the first and second electrical stimulation $\left(\mathrm{C}_{2} / \mathrm{C}_{1}\right)$. In the epididymal site, $10^{-6} \mathrm{M}$ NKA did not influence the ${ }^{3} \mathrm{H}$ efflux but enhanced ${ }^{14} \mathrm{C}$ efflux (Fig. 5A), which may be attributed to ${ }^{14} \mathrm{C}$ efflux derived from smooth muscle. Indeed the ATP component of stimulation-induced contraction in the epididymal site was enhanced to a similar extent (Fig. 5B), and the increase in ${ }^{14} \mathrm{C}$ efflux was not blocked by the treatment of $10^{-6} \mathrm{M}$ guanethidine (data not shown). However, in the prostatic site, the release of NE or ATP was constant, but the contraction was enhanced. Furthermore, the contractile responses to exogenously applied $10^{-6} \mathrm{M} \mathrm{NE}$ or $10^{-4} \mathrm{M}$ ATP were augmented by $10^{-6} \mathrm{M}$ NKA in both sites, but the amplitude of this augmentation in the prostatic site was greater than that in the epididymal site (data not shown). 
A. Release

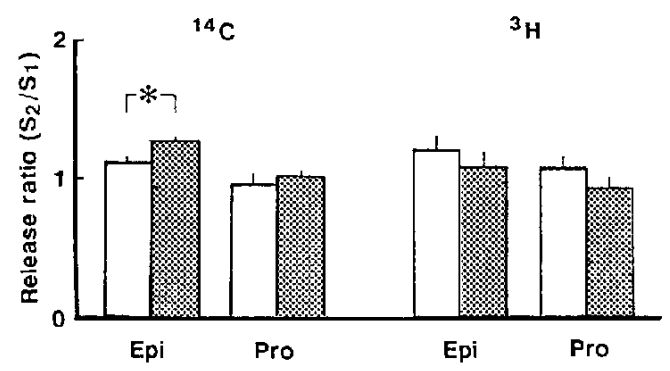

B. Contraction

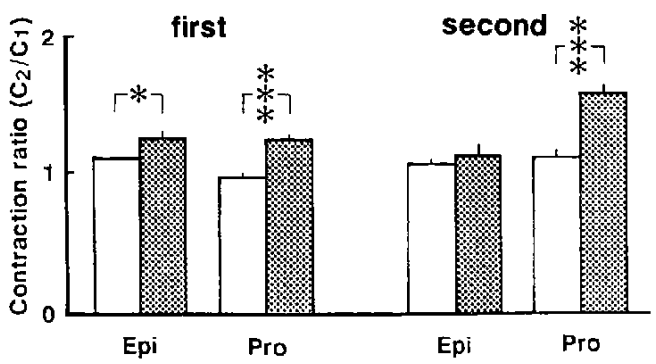

Fig. 5. Effects of $10^{-6} \mathrm{M}$ NKA on ${ }^{14} \mathrm{C}$ and ${ }^{3} \mathrm{H}$ efflux (A) and contractions induced by released ATP or NE (B) evoked by electrical stimulation in the rat vas deferens previously loaded with $\left[{ }^{14} \mathrm{C}\right]$ adenosine or $\left[{ }^{3} \mathrm{H}\right]$ $\mathrm{NE}$, respectively. The ordinate in $(\mathrm{A})$ indicates the radioactive efflux $\left(\mathrm{S}_{2} / \mathrm{S}_{1}\right)$ and in $(\mathrm{B})$, the contraction $\left(\mathrm{C}_{2} / \mathrm{C}_{1}\right)$ which is expressed as a ratio between the response of two consecutive stimuli. First: the initial twitch contraction attributable to released ATP; second: the following sustained contraction attributable to released NE. Open (control) and stippled (NKA-treated) columns indicate the ratio of released radioactivity between the first and second electrical stimulation in the absence or presence of NKA, respectively; and vertical bars indicate the S.E. of four experiments. Asterisks indicate a significant difference from the control value $\left({ }^{*}: \mathrm{P}<0.05, * * *: \mathrm{P}<0.001\right.$ ).

\section{DISCUSSION}

Although $10^{-6} \mathrm{M}$ prazosin and $10^{-5} \mathrm{M} \alpha, \beta-$ me-ATP, which completely inhibited NE- and ATP-induced contractions, respectively, had no effects on NKA-induced contractions in the epididymal site, the two antagonists significantly reduced the contraction induced by high concentration of NKA in the prostatic site. The inhibitory effects of prazosin, however, may be attributable to its $\mathrm{Ca}^{2+}$ channel blocking effect (15) or membrane stabilizing effect. We have shown previously that nicardipine strongly inhibited high concentrations of NKA-induced contractions (13). The inhibitory effect of $\alpha, \beta$-me-ATP can be explained by the blockade of enhancement of contraction induced by ATP, which may be released by high concentration of NKA from the postsynaptic site. The evidence that treatment of guanethidine did not affect NKA-induced contractions in the prostatic site, also suggests that released ATP from the postsynaptic site as a result of membrane depolarization or contraction partially contributed to the NKA-induced contractions. To investigate the effects of NKA on the release of neurotransmitters more precisely, release of radioactivities after loading the tissue with $\left[{ }^{3} \mathrm{H}\right] \mathrm{NE}$ and $\left[{ }^{14} \mathrm{C}\right]$ adenosine was studied.

NKA did not affect either spontaneous or electrical stimulation-evoked release of ${ }^{3} \mathbf{H}$ efflux. The spontaneous ${ }^{14} \mathrm{C}$ efflux from the epididymal site was not changed, but slightly increased in the prostatic site by $10^{-6} \mathrm{M}$ NKA. However, the increase of ${ }^{14} \mathrm{C}$ efflux in the prostatic site was still observed in the presence of guanethidine, indicating that the origin of NKA-induced increase in ${ }^{14} \mathrm{C}$ efflux was not a presynaptic site but a postsynaptic site. High concentrations of NKA induced membrane depolarization and evoked ATP release from postsynaptic smooth muscle. These results suggest that NKA-induced contraction consists of both a direct action on $\mathrm{NK}_{2}$ receptors located on the postsynaptic smooth muscle and indirect action of ATP released from smooth muscle. Such an indirect action of ATP has been demonstrated in guinea pig ileum (16).

Similar evidence suggesting the release of ATP from postsynaptic sites as well as neuronal ones was presented in the rabbit kidney (17), the rat caudal artery (18) and rat vas deferens (4). However, it is not always easy to ascertain whether the source of ATP is nerves or muscles. Release of ATP in response to 
neuronal stimulation was shown to be predominantly, if not entirely, of neuronal origin in the guinea pig bladder and taenia coli, where contractions and relaxations produced by direct muscle stimulation or NE, failed to release ATP (19). In the guinea pig vas deferens, release of ATP in response to sympathetic nerve stimulation was not significantly reduced by depletion of NE stores by reserpine (7) or by depression of the mechanical responses with the combination of prazosin and $\alpha, \beta$-me-ATP (9). Furthermore, it has been also demonstrated that ATP is slightly released from presynaptic nerve endings together with NE, and a significant amount of ATP was released secondarily from the postsynaptic site as a result of released $\mathrm{NE}$ action via $\alpha_{1}$-adrenoceptors localized on the smooth muscle in rat vas deferens (14). Since NKA did not affect the release of NE in the present study, the possibility that the increase of ATP release is mediated by augmented release of NE can be excluded.

These results indicate that the physiological role of NKA is not likely the promotion of the neurotransmission on a presynaptic site but the facilitating effect on a postsynaptic site without influencing presynaptic sites in the prostatic site of rat vas deferens, while the site of action of NKA in the epididymal portion was clearly localized only in the postsynaptic membrane.

As mentioned above, NKA had a facilitating effect on the postsynaptic site with no influence on presynaptic sites in the prostatic site of rat vas deferens. Substance $P$ (SP) and NKA (NKA was about 300 times more potent) enhanced twitch responses induced by field stimulation at $0.1 \mathrm{~Hz}$ and NE- and ATPinduced contractions in both sites of rat vas deferens without causing desensitization, although it was not determined definitely whether a pre- or postsynaptic site was involved in the effect of NKA (11). It has been recently reported that $\mathrm{SP}$ enhanced responses to $\alpha, \beta$-me-ATP with no effect on the release of either NE or ATP in guinea pig vas deferens (20).
In conclusion, NKA has no effect on presynaptic nerve terminals in both sites and potentiates the effects of transmitters in the prostatic site, indicating that NKA modulates neurotransmission.

\section{REFERENCES}

1 Diez-Guerra, F.J., Sirinathsinghji, D.J.S. and Emson, P.C.: In vitro and in vivo release of neurokinin A-like immunoreactivity from rat substantia nigra. Neuroscience 27, 527-536 (1988)

2 Kimura, S., Okada, M., Sugita, Y., Kanazawa, I. and Munekata, E.: Novel neuropeptides, neurokinin alpha and beta is isolated from the porcine spinal cord. Proc. Japan. Acad. 59, 101-104 (1983)

3 Minamino, N., Kangawa, K., Fukuda, A. and Matsuo, H.: Neuromedin L: a novel mammalian identified in porcine spinal cord. Neuropeptides 4, $157-166$ (1984)

4 Fredholm, B.B., Fried, G. and Hedqvist, P.: Origin of adenosine released from rat vas deferens by nerve stimulation. Eur. J. Pharmacol. 79, 233-239 (1982)

5 Allcorn, R.J., Cunnane, T.C. and Kirkpatrick, K.: Actions of alpha, beta-methylene ATP and 6hydrocydopamine on sympathetic neurotransmission in the vas deferens of the guinea-pig, rat and mouse. Br. J. Pharmacol. 89, 647-659 (1986)

6 Kasakov, L., Ellis, J., Kirkpatrick, K., Milner, P. and Burnstock, G.: Direct evidence for concomitant release of noradrenaline, adenosine-5'triphosphate and neuropeptide $Y$ from sympathetic nerves supplying the guinea-pig vas deferens. J. Auton. Nerv. Syst. 22, $75-80$ (1988)

7 Kirkpatrick, K. and Burnstock, G.: Sympathetic nerve-mediated release of ATP from the guineapig vas deferens is unaffected by reserpine. Eur. J. Pharmacol. 138, 207-214 (1987)

8 Westfall, D.P., Stitzel, R.E. and Rowe, J.N.: The postjunctional effects and neuronal release of purine compounds in the guinea-pig vas deferens. Eur. J. Pharmacol. 50, 27-38 (1978)

9 McGrath, J.C.: Adenosine and non-adrenergic components in the contractile responses of vas deferens to a single indirect stimulus. J. Physiol. (Lond.) 283, 23-39 (1978)

10 Tayler, D.A., Wiese, S., Faison, E.P. and Yarbrough, G.G.: Pharmacological characterization of purinergic receptors in the rat vas deferens. J. Pharmacol. Exp. Ther. 224, 40-45 (1983)

11 Moritoki, H., Iwamoto, T., Kanaya, J., Ishida, 
Y., Ando, K. and Kitagawa, K.: Capsaicin enhances the non-adrenergic twich response of rat vas deferens. Br. J. Pharmacol. 92, 469-475 (1987)

12 Tousignant, C., Dion, S., Drapeau, G. and Regoli, D.: Characterization of pre- and postjunctional receptors for neurokinins and kinins in the rat vas deferens. Neuropeptides 9, 333 - 343 (1987)

13 Nagata, K., Saito, H. and Matsuki, N.: Efficient $\mathrm{Ca}^{2+}$ mobilization induced by neurokinin $\mathrm{A}$ in rat vas deferens. Eur. J. Pharmacol. 204, 295-300 (1991)

14 Vizi, E.S. and Burnstock, G.: Origin of ATP release in the rat vas deferens: concomitant measurement of $\left[{ }^{3} \mathrm{H}\right]$ noradrenaline and $\left[{ }^{14} \mathrm{C}\right] \mathrm{ATP}$. Eur. J. Pharmacol. 158, 69-77 (1988)

15 Atlas, D. and Adler, M.: Alpha-adrenergic antagonists as possible calcium channel inhibitor. Proc. Natl. Acad. Sci. U.S.A. 78, 1237-1241 (1981)

16 Katsuragi, T., Tokunaga, T., Usune, S. and Fufukawa, T.: A possible coupling of postjunction- al ATP release and transmitters' receptor stimulation in smooth muscle. Life Sci. 46, 1302-1307 (1990)

17 Fredholm, B.B. and Hedqvist, P.: Release of ${ }^{3} \mathbf{H}-$ purines from ${ }^{3} \mathrm{H}$-adenine labelled rabbit kidney following sympathetic nerve stimulation and its inhibition by alpha-adrenoceptor blockade. Br. J. Pharmacol. 64, 239-247 (1978)

18 Westfall, D.P., Sedaa, K. and Bjur, R.A.: Release of endogenous ATP from rat caudal artery. Blood Vessels 24, 125-132 (1987)

19 Burnstock, G., Cocks, T., Kasakov, L. and Wong, H.: Direct evidence for ATP release from nonadrenergic, non-cholinergic (purinergic) nerves in guinea-pig taenia coli and bladder. Eur. J. Pharmacol. 49, $145-149$ (1978)

20 Ellis, J.L. and Burnstock, G.: Modulation of neurotransmission in the guinea-pig vas deferens by capsaicin: involyement of calcitonin gene-related peptide and substance $\mathrm{P}$. Br. J. Pharmacol. 98, $707-713(1989)$ 